\title{
INDÚSTRIA CULTURAL E EDUCAÇÃO: O NOVO CANTO DA SEREIA*
}

\author{
Filipe CePpas ${ }^{* *}$
}

O

livro de Zuin, publicação de sua tese de doutorado, é uma contribuição à reflexão sobre a importância da Escola de Frankfurt - de Adorno em especial - para uma crítica das teorias pedagógicas e para a práxis pedagógica. Práxis que o autor não limita ao contexto escolar, mas a concebe em termos de articulaçóes, teóricas e práticas, do ideal mais amplo de formação que foi se consolidando na história das sociedades ocidentais, no sentido da ilustração e da emancipação. Situado no âmbito da filosofia da educação, o livro procura apresentar a contribuição da Escola de Frankfurt para a análise dos múltiplos aspectos históricos, sociais e psicológicos desse ideal de formação que, supostamente, subjaz, ainda que não necessariamente de modo explicitado ou consistente, qualquer proposta ou prática pedagógica.

O autor, que tem formação em Psicologia, enfatiza a dimensão psicológica dos processos que envolvem as interaçôes/oposiçôes entre indivíduo e sociedade, no que se refere à busca da realização do esclarecimento através da educação - i.é, a perspectiva da conquista, por parte dos indivíduos, de um agir racional, autônomo e responsável, que simultaneamente pressupõe e visa a democratização do acesso aos bens

\footnotetext{
* Resenha do livro de Antônio A. S. Zuin (São Paulo: Autores Associados/FAPESP, 1999).

** Doutorando em Educação na Pontifícia Universidade Católica do Rio de Janeiro (PUC-RIO). E-mail: fceppas@terra.com.br
} 
materiais e simbólicos, na esperança de compatibilizar justiça e liberdade. Podemos destacar dois eixos fundamentais do de Zuin: (1) as distâncias e as relações determinantes entre a desigualdade material e os diversos sentidos que uma suposta democratização dos bens simbólicos adquire em nossa sociedade, a partir do desenvolvimento da indústria cultural; e (2) os desafios prático-conceituais que se colocam para uma perspectiva criticamente comprometida com o ideal pedagógico emancipatório, diante das conseqüências potencialmente destrutivas daquelas distâncias e relações.

Um dos pontos de inflexão importantes do trabalho de Zuin é a identificação da idéia de formação como o "correlato subjetivo da própria cultura" (p. 55); ou, melhor dito: “(...) é dessa tensa relação entre a dimensão objetiva e subjetiva da cultura que se origina o conceito de formação, ou seja, a subjetividade objetivada nos produtos humanos pela intervenção do agir formativo necessita tanto de um momento de distanciamento quanto de aproximação da realidade que transforma o sujeito tanto quanto é transformada pelo exercício da atividade racional" (idem). Assim, pode-se perceber a difícil dialética dos impulsos formativos na dinâmica cultural. A arte, tomada como instância cognitivamente privilegiada da cultura, pressupõe o relativo afastamento das condições sociais como condição necessária de sua própria identidade e realização, mas este não pode ser absolutizado, sob o risco de ceder à afirmação dos mecanismos de dominação que imperam na ordem social. Por outro lado, a própria idéia de dominação não pode ser negativamente absolutizada, na medida em que se reconheça sua importância nos processos de sublimação dos impulsos vitais na formação psicológica dos indivíduos e na instituição da cultura. Nesta dialética, por fim, Zuin chama a atenção para o perigo de se absolutizar ainda uma tendência de adaptação ao existente, que é a "(...) aversão a qualquer possibilidade de uma atitude de distanciamento em relação ao mundo fenomênico que poderia encetar reflexão e questionamento da barbárie" (p. 57).

A tese assumida pelo autor se apóia na importância conferida à arte pelos frankfurtianos como momento cognitivo revelador desta dialética. Assim, a tese é apresentada através de um paralelismo:

(...) se, para Adorno, a verdadeira experiência estética permite a reapropriação do mimético que se relaciona com o construído sem que ambos sejam absolutizados, da mesma forma, afirmar-se-ia que, na dimensão pedagógica, uma concepção de educação que pretende ser emancipatória poderia auxiliar na realização da auto-reflexão crítica da formação que se converteu na semiformação. (p. 6) 
Em primeiro lugar, é preciso esclarecer o que o autor está chamando de mímesis, que é a "atitude do indivíduo que, para poder livrar-se do medo do desconhecido (leia-se do natural), renuncia a diferenciar-se da entidade com a qual confronta o seu próprio ego e opta por imitá-la, negando a sua própria identidade" (p. 13). Formulado originalmente no contexto da análise da identidade entre mito e esclarecimento, feita por Adorno \& Horkheimer, com base nas aventuras de Ulisses, esse mecanismo é transposto para o comportamento dos consumidores da indústria cultural, os pseudo-indivíduos, na terminologia adorniana, que optam por imitar os comportamentos regressivos que se mostram menos conflitantes com uma realidade que se pressente insuperável.

Ao retomar a questão da arte como dimensão exemplar entre os "produtos simbólicos", Zuin apropria-se da reflexão de Adorno \& Horkheimer acerca da liberdade da arte dita "séria" com relação ao existente. Esta liberdade, esse caráter construído, mediatizado da representação artística, se mantém "fiel à causa das classes inferiores", precisamente pela não submissão "aos fins da falsa universalidade", vale dizer, pela recusa à "submissão quase que total ao seu caráter de valor" (p. 123). Com esta liberdade, a arte reflete sua dívida para com os ideais da emancipação, seu compromisso com a universalidade, que envolve os ideais de justiça e liberdade para todos. $\mathrm{O}$ existente, ao contrário, se impóe à maioria, em toda a sua falsa universalidade, através da indústria cultural, como negação dissimulada desses valores, como recalque e transfiguração dos desejos que supostamente deveriam ser atendidos pela cultura. Mas a arte apenas se afirma como distanciamento, negação e crítica do existente graças ao próprio existente, pois "é esse mundo desigual que produz as condições materiais para a consagração do poder de crítica da arte" (idem). Entendese, assim, que a verdadeira experiência estética seja aquela que "permite a reapropriação do mimético que se relaciona com o construído sem que ambos sejam absolutizados". A absolutização de um ou de outro representaria seja um distanciamento pseudocrítico da arte dita "séria" frente ao existente (hipostasiação do momento de negação do existente) - sem que, entretanto, ela sequer possa se ver totalmente livre de seus influxos -; seja o enrijecimento daqueles impulsos miméticos inevitáveis, que respondem ao medo do desconhecido, à permanência do mito - da dominação da natureza que se desdobra em dominação do homem sobre o homem - no interior do próprio esclarecimento (hipostasiação do momento de adaptação ao existente).

Dito isto, a segunda parte da hipótese - a saber: “(...) da mesma forma (...), na dimensão pedagógica, uma concepção de educação que 
pretende ser emancipatória poderia auxiliar na realização da auto-reflexão crítica da formação que se converteu na semiformação" - torna-se mais clara. Verifica-se, em primeiro lugar, a necessidade de uma compreensão ampla da idéia de educação emancipatória, onde a educação escolar só pode ser pensada em conexão com os diversos aspectos formativos que atravessam a sociedade como um todo. Em segundo lugar, trata-se do esforço para identificar e analisar os mecanismos que impedem que propostas educativas tenham um impacto de fato relevante na busca pela construção de uma práxis educativa que leve a sociedade à realização do ideal de emancipação e esclarecimento. Isto remete à tensão entre distanciamento do e adaptação ao existente, mencionada acima, e pressupōe, necessariamente, uma teoria que transcenda os limites de teorias e práticas pedagógicas fechadas em si mesmas, no sentido de demandar uma análise do contexto social, econômico e político em que se inserem esses processos formativos. Assim, numa formulação certamente por demais sintética, pode-se dizer que a tese de Zuin concentrase, primordialmente, na exortação para a manutenção, por parte das teorias e práticas pedagógicas, de um olhar crítico para o "duplo caráter da cultura”, i.é, que leve em conta a complexa interdependência dos momentos de negação do e adaptação ao existente.

Das idéias de Adorno, destacam-se os elementos que seriam necessários à construção de qualquer pedagogia realmente comprometida com a superação dos problemas colocados pelo confronto entre o ideal de esclarecimento e as condições atuais das sociedades ocidentais: o tempo necessário para a reflexão; a continuidade entre conteúdos e valores assimilados pelos educadores e educandos, em respeito à natureza histórica e interdependente das experiências possíveis; o respeito também à interconexão entre os processos educativos escolares e não-escolares; e, principalmente, a atenção redobrada para com o descompasso inevitável entre teoria e prática, do qual são parte constitutiva as tensões entre a adaptação ao (ou assimilação do) real e a sua crítica. Vale mencionar, ainda, a apresentação que Zuin faz, no final do quarto capítulo, de três autores frankfurtianos que desenvolvem, atualmente, na Alemanha, reflexóes e propostas pedagógicas baseadas em Adorno: Andreas Gruschka, Norbert Hilbig e F. Hartmut Paffrath; o segundo envolvido na prática de uma escola adorniana, a Escola Theodor W. Adorno, na cidade de Elze. Todos os três desenvolvem reflexóes e práticas muito interessantes que servem para exemplificar alguns aspectos dos elementos destacados acima. Em especial, ressalta-se o conceito de uma pedagogia radicalmente dialógica, idéia que, se não é inovadora, aparece de modo original no contexto das teorizações de Adorno em torno da educação. 
Diante do intenso esforço teórico levado a cabo pelo autor, talvez fosse excessivo cobrar uma articulação da análise levada a cabo com exemplos mais representativos do amplo cenário das teorias e práticas pedagógicas hoje existentes, para além dos três autores mencionados acima, que já partem de uma visão educacional de inspiração adorniana. É possível dizer que, em função da ausência de uma tal articulação, a força da tese de Zuin revela também uma fraqueza, na medida em que os objetivos mesmos do autor indicam um tal caminho e deveriam leválo a um maior esforço neste sentido. Esta ausência se casa com o tratamento dos elementos empíricos elencados por Zuin para exemplificar ou desenvolver suas análises. Em alguns momentos, este material parece quase apenas atualizar exemplos dos autores trabalhados (como o homem que ama mais o carro do que a esposa); noutras, ele é simplesmente visto sob uma ótica um tanto reducionista (a prática do uso dos piercings como mero ritual sadomasoquista de uma juventude regredida). Neste sentido, Zuin parece apegar-se a limites da apreciação historicamente determinada do próprio Adorno (o que fica evidente quando Zuin assume que "qualquer continuidade do vínculo entre o pensamento e o questionamento da realidade é desestimulada pelos ditames da indústria cultural" (p. 73), em contraste com momentos mais dialéticos e refinados de sua especulação teórica e, claro, do próprio Adorno).

Parece difícil, hoje, subscrever o caráter totalizante e monolítico da visão de Adorno sobre a indústria cultural, incapaz de enxergar elementos que não fossem senão regressivos em suas manifestações concretas particulares - ainda que o método e os objetivos do filósofo alemão tornem-se cada vez mais estimulantes, seja somente pela genialidade com que trazem à tona o incômodo com a ordem existente. Esses eventuais limites não diminuem, de modo algum, o resultado final do esforço empreendido por Zuin, que é o de explicitar, articular e sistematizar aspectos essenciais do instrumental frankfurtiano na análise dos dilemas do esclarecimento, buscando desenvolver uma análise-síntese da transformação do conceito de formação em semiformação no contexto da semicultura e sua importância para a reflexão e a prática pedagógicas. Seus limites e tensões correspondem a desafios teóricos e práticos latentes para quem se preocupa com a questão das condições de uma educação voltada para a emancipação. 